\title{
Process Cost Management of Alzheimer's Disease
}

\author{
Hana Tomaskova ${ }^{1, *,+} \mathbb{D}$, Martin Kopecky ${ }^{1,+}$ and Petra Maresova ${ }^{2,+} \mathbb{D}$ \\ 1 Department of Information Technology, Faculty of Informatics and Management, University of Hradec \\ Kralove, Rokitanskeho 62, 50003 Hradec Kralove, Czech Republic \\ 2 Department of Economics, Faculty of Informatics and Management, University of Hradec Kralove, \\ Rokitanskeho 62, 50003 Hradec Kralove, Czech Republic \\ * Correspondence: hana.tomaskova@uhk.cz \\ + These authors contributed equally to this work.
}

Received: 24 July 2019; Accepted: 27 August 2019; Published: 2 September 2019

\begin{abstract}
Summary: Determining the cost of healthcare and social care for patients is a crucial issue for many parties; therefore, both public and private payments play a decisive role in patient care. The article deals with the analysis of the possibilities of the simulation of costs related to Alzheimer's disease. This disease is highly variable, and the cost items vary considerably. Therefore, it is necessary to use simulation methods. The results of simulation models can then be implemented in sophisticated methods working with activity costs. Findings: Models for health and social care are specific. No significant re-engineering is expected in this area, so the models must be unambiguous and easy to understand for all representatives involved. Modeling of business processes is thus a suitable means for analysis in this area. The process cost calculation is built on two simulation models. The first model is the Business Process Model and Notation (BPMN), the results of which are verified in the system dynamics model created in the stock and flow diagram. The simulations results give us appropriate values for calculating the total activity-based costs of AD. Applications: The practical part of this article deals with the identification of costs related to Alzheimer's disease and their allocation concerning remedies. Based on this information, models for Alzheimer's disease process cost management are developed. Results: The BPMN simulation was performed for 100 passes through a fixed-length phase process. The duration of each phase was set at 48, 108, and 40 months. Five simulations were set up, each Mini-Mental State Examination (MMSE) score set, which affected the passage through the process. Software Stella Professional was used for simulations for constant MMSE score values for the home and facility options. The values are as follows: MMSE $5=1331.26 €(1627.72 €) ;$ MMSE $15=1202.72 €(1102.02 €) ;$ MMSE $25=1051.24 €(848.91 €)$. Conclusions: Both AD models created in this article produce comparable results, although each of them works on a different principle. The results are based on the selection of original data, and at the same time, these models point to the processes and subprocesses that lead to the costs. The description, specifications, and possible values of partial costs are crucial knowledge for persons in the management functions of public administration and self-government in the area of finance and management not in the field of specific diseases.
\end{abstract}

Keywords: Alzheimer's disease; process cost management; BPMN; system dynamics; simulation

\section{Introduction}

The worldwide trend in the number of mentally ill adults, such as Alzheimer's in the age group of 65 years and older, poses a significant therapeutic and care challenge as providers are forced to reduce costs while maintaining or improving the quality of care [1]. Addressing the costs of diseases is a topical problem not only for hospital facilities, but also for patient families. The cost of medicines and patient treatment is steadily increasing, while reimbursements paid by insurance providers are 
fixed according to pre-defined diagnostic groups [2]. Costs need to be solved more comprehensively, and therefore, it has recently become necessary to address the costs of activities.

Process management does not cure the patient's problems, but this approach enables modernizing processes or re-engineering systems to support new clinical practices, regulatory standards, cost recovery methods, and the like. Healing processes are very complex, and their graphical visualization facilitates their management and improvement. Overall, process management in global health care reduces time to change, ensures visibility of the entire management and decision-making life cycle, and enables you to respond effectively to non-standard situations [3].

Alzheimer's Disease (AD) was chosen as a disease whose course is highly variable, and the cost items vary considerably. Alzheimer's disease is a long-term neurodegenerative disease characterized by a creeping onset that may not be evident at first sight. The standard progression is a relatively long-lasting disease and usually lasts for 6-16 years. People with this disease are gradually faced with various memory problems, which continue to the stage where they meet communication and daily life problems. Ultimately, the patient is entirely dependent on others' care. For this article, it is crucial to identify the different stages of the disease and to define medical and nursing care and the associated costs. Due to the high variability of the disease and treatment, it is necessary to use simulation methods that allow the use of probabilistic and statistical methods to work with random elements in a mathematical model.

When selecting the modeling approach, there is a need to consider predominantly the context of the decision problem or the relationship between inputs and the outcomes. Modeling of AD mostly deals with chemical processes [4-7], predicting the number of people with Alzheimer's disease or dementia in different locations [8-14], and the economic assessment of a particular treatment at a particular stage of the disease [15-18]. The paper [19] considered the methods available to model Alzheimer's disease. The authors found that most of them are statistical models predicting the progression of Alzheimer's disease using a measure of cognitive function. The authors of [20] used Markov models, which are a form of life-table and require age-specific death rates, as well as transition rates between disease stages. Another paper [21] used a discrete event simulation of Alzheimer's disease progression. Many population-based models are built mainly on the opinions of experts, but different computational techniques can also be used for modeling population dynamics, such as system dynamics [22-24], agent-based modeling [25,26], genetic algorithms [27,28], and programming, evolutionary computation, and strategies [29]. Many varied methods can be used to model dynamic systems, such as Discrete Element Modeling (DEM) [30] or population balance modeling [31,32]. A comparison of the three most common approaches for Alzheimer's disease modeling (prediction) was described in [10].

Health cost models use sophisticated tools, mainly because managing these care plans is often a complicated task. For example, the clinical path timeline prescribes an expected treatment plan for a group of patients with a specific diagnosis or undergoing a particular clinical procedure. It outlines a time-specific treatment plan recommending tests and therapies based on a combination of clinical practice consensus and evidence from the scientific literature [33]. The authors of [2] pointed out that the use of BPM leads to real benefits in terms of resource optimization and quality improvement.

The use of BPM as a means to improve quality in process control automation was highlighted in [34]. This approach will reduce possible human errors. Thanks to BPM, it is possible to (1) identify the key IT needs for the process of individual treatment of mental illness, (2) interconnect and coordinate multiple sources of information, (3) link the different stages of the disease to the needs of patients and demonstrate them in an understandable form to all stakeholders, and (4) incorporate the cost of individual health care processes. This notation is user-friendly, easy to read, and well received across many fields. It enables displaying not only complex systems, but also simple basic processes. For health care [35], it is recommended to create models as transparent as possible, in simple procedures to maintain an understanding of all parties involved. 
The present article is designed as an analysis of how it is possible to address the cost of Alzheimer's disease by using process models in the Business Process Model and Notation (BPMN) for process valuation by Activity-Based Costing $(\mathrm{ABC})$. The article is divided into the following sections:

- Section 2 introduces basic theoretical knowledge. Section 2.1 represents the necessary knowledge of Alzheimer's disease that was used for the process model. In Section 2.2 are mentioned approaches to cost management.

- Section 3 presents the research proposal and the main steps leading to the results. In the first Section 3.1, the study design is outlined. In the second Section 3.2 are two modeling approaches, Business process Model and Notation (BPMN) and System Dynamics (SD), and the Activity-Based Costing method $(A B C)$ is introduced. The third Section 3.3 is devoted to the main cost items of Alzheimer's disease.

- Sections 4 and 5 are devoted to the research results. Cost causalities in the health and welfare systems are presented, and the need for identification and estimation of cost values entering the whole process of care for Alzheimer's patients is highlighted.

- Section 6 summarizes the benefits of this research.

\section{Theoretical Background}

The key to specifying BPMN processes and identifying costs is a detailed specification of the activities and tasks that need to be ensured in the treatment and care of people with dementia. Their specification is made concerning the stage of the disease, which fundamentally influences the list of activities requiring assistance and the amount of medical care. The specification also reflects the basic cost classification given in the Methodology Section. The two classifications (activities and costs) must correspond in the following models. This will prevent redundancies in calculations or future data collection as part of the use of the model.

\subsection{Basic Aspects of Alzheimer's Disease}

Alzheimer's disease is the most common cause of dementia. The Alzheimer's web site by [36] states that AD afflicts approximately $60 \%$ of people suffering dementia, and [37] speaks about $56 \%$. The website [37] defines AD as a condition that "disturbs part of the brain and causes the decline of so-called cognitive functions-thinking, memory, judgment. It is the most common cause of dementia, which leads gradually to the patient's dependence on the everyday help of another person."

Several medical examinations are used to diagnose Alzheimer's disease. It is primarily magnetic resonance, where brain changes are monitored. Occasionally, cerebrospinal fluid or blood tests are used. For this work, an examination called the Mini-Mental State Examination (MMSE) is the fundamental test $[38,39]$. This test is performed by a psychiatrist with the patient, resulting in a score of $30-0$ points. From this value in the model, the selected therapeutic agents are based on the assessment of their effectiveness.

\subsubsection{Alzheimer's Disease: Stages}

Three primary Alzheimer's disease stages, which are then considered in the models, will be defined in this subsection. Unfortunately, the naming of different Alzheimer's disease stages differs in various sources. For this reason, in this work, the stages will be marked with Roman numerals. The following information has been taken from [40].

\section{Stage I (1-4 years from the onset of illness)}

There are difficulties in dealing with new experiences. The patient has difficulty orienting in new areas, using new devices, or following new procedures. Similarly, short-term memory problems occur. The patient also makes more trivial mistakes of inattention and begins to experience complications in logical operations. This phase is realized by the patient in the form of "something is not right". 
There may also be psychological problems that cause mood swings to depressed states. Another symptom of Alzheimer's disease and dementia is the emerging communication problems where the patient is unable to find the right words or names during communication. For other people around the patient, the above changes may not seem like a disease, but may be considered a natural manifestation of age.

\section{Stage II (2-10 years from the onset of illness)}

At this stage, it is already clear that this is not an ordinary course of aging. There are difficulties in performing routine activities and patient-centered locations. This is associated with more significant brain damage that leads to the inability to concentrate and "slows down" brain function so much that the patient forgets what he/she wants to do. The patient needs assistance with dressing and personal hygiene. Communication with the affected person is already very complicated, and psychological problems deteriorate into hallucinogenic and delusional states. There is also a change in the personality with a tendency to higher self-esteem. Short-term memory is almost non-functioning, while the patient remembers his/her youth and sometimes lives in his/her younger age.

\section{Stage III (7-14 years from the onset of illness)}

This is the last stage of the illness, in which the patient is already wholly dependent on other people. This stage ends with the patient's death. It is a complete loss of memory and inability to do the simplest tasks. The patient must be fed and cleaned and remains completely immobile. Mood swings, apathy, and latent states occur. Communication is complicated, usually only through individual words. Generally, the patient does not recognize any known objects or faces.

\subsubsection{Alzheimer's Disease: Remedies}

Because Alzheimer's disease is incurable, most of the remedies for its symptoms are focused on slowing the course of the illness or mitigating the consequences. In the last phase, most of the activities are aimed at ensuring the highest possible dignity for the patient and satisfaction for the rest of their lives. The essential source of information on this topic was consultations with MUDr. Jiři Kuchyňka, and cited sources supplemented his information.

\section{Pharmacological treatment}

The main medication used to alleviate Alzheimer's disease includes a group of drugs called the cognitives. "Cognitives are substances whose mission is to improve cognitive functions-attention, learning, memory, etc. These cognitive functions are particularly affected by dementia" [41]. The cognitives are divided into two groups according to their active substance. The first group includes drugs of the acetylcholinesterase inhibitor group. This group contains donepezil with the active content of the same name, which is used in a milder form of dementia (up to 20 points in the MMSE test). For severe forms of dementia, memantine is used. This drug belongs to the "NMDA receptor antagonist" group. The drug is used at an MMSE score of fewer than 20 points.

Different studies then showed different values for how severe the disease was, and in the same way, they differed in their opinions regarding the limit when the medication should be administered. In this paper, the 10-point boundary was considered for simplicity. The research was consistent with the need to monitor the patient for 2-3 months and evaluate the effect of the medication on cognitive behaviors. Likewise, it was necessary to use the medication in increasing doses. The MMSE test results were taken as the primary measure of drug efficacy. When the patient in this test reached a score worse by two points than the previous score, cognitive therapy was regarded as ineffective. At this point, it was necessary either to change the cognitive drug for a variant with another active substance or to discontinue the medication.

This also has an economic impact because when the cognitive continues to decline, Czech health insurers do not contribute to the treatment [42]. 


\section{Formal care activities}

A key aspect of slowing the progress of Alzheimer's disease is patient care. The aim of this care should be to preserve the patient's enjoyment of life and try to maximize the patient's autonomy. At a later stage, care is primarily focused on protecting health and maintaining a reasonable quality of life. It follows from the above that any care is appropriate, and much of the care can be transferred to the family. To a large extent, it can help to involve the patient in routine activities that he/she had previously performed on his/her own and is now unable to do without help. These are activities such as cooking and the like. From this paper, activities that cannot be transferred to the family are essential and must be carried out by specialists in the patient's area. The following is a list of possible activities with the patient $[43,44]$. The decisions that will be made with the patient then depend on the specific development of the disease.

- Psychotherapy

- Art therapy

- Canistherapy

- Pet therapy

- Dance and movement activities

- Ergotherapy

- Reminiscence

- Validation therapy

- Cognitive therapy

- Kinesiotherapy

\section{Other expenditure activities}

This section includes all activities that may generate additional costs in connection with Alzheimer's disease. As a rule, this expenditure relates to the care that the patient receives from the family, or, where appropriate, cases when the costs are different from a healthy life. Again, there is a list of potential expenses incurred due to Alzheimer's disease [44].

- Hygienic aids

- Special dietary requirements

- Household equipment adjustment

- Rehabilitation and assistance aids

- Material for creative therapies

- Compensation aids

\subsection{Approaches to Cost Measurement}

Concerning the stages as mentioned above of illness and activity, whether medical or non-medical care, they must be adequately linked to the relevant cost groups. This is the only way to avoid repetition of items, activity, and misrepresentation of the overall economic burden. Costs can theoretically be divided into direct and indirect costs, according to [45]. Direct costs are tied to a specific type of business and will be incurred in establishing and operating a medical program. These activities include treatment costs (outpatient and inpatient), medicines, doctor visits, diagnostic and laboratory tests, medical devices, rehabilitation, and many other items. Indirect costs are hard to express because they are mostly related to the care time spent on the patient by family or informal carers. They are a loss of productivity of the patient and the patient's caregiver and loss of productivity due to the premature death of the patient. The author of publication [46] pointed out the necessity of the measurability of costs in specific units. Practically, it is possible to determine the extent or size of resources consumed during treatment or care. Costs can thus be divided according to the specification into detailed costs (medicines, tests, childcare costs, transportation 
to a doctor), diagnostic costs, average daily costs for treatment of different degrees of illness, and average regular costs. More differences cannot be found in other studies. In the Czech survey [47], direct health costs included outpatient examinations, hospitalization costs, institutionalization costs, pharmacological and non-pharmacological treatment costs, emergency services costs, nursing services costs, rehabilitation, and laboratory tests. The study [48] divided the costs between the direct costs of regular medical care (medical care, outpatient examinations, and medicines) and non-medical care. Similarly, the publication [49] divided the costs of regular medical care, which newly included institutional care, rehabilitation, medical equipment, non-medical services, and home nursing care, and informal care (time spent by caregivers with their clients).

Some authors in their publications $[45,50]$ focused on describing cost-cutting according to resource consumption in different sectors, consumption of health resources, consumed resources by the patient and their family, resources consumed in another industry, and resource-consuming care. The expression of economic burden is also complicated internationally by specific registers, which do not allow the general use of the potential of studies for their mutual comparison.

It follows from the above comparisons and the documents on costing in health care [51] and economic theories that the initial cost breakdown should be direct and indirect. The direct costs of Alzheimer's disease will be broken down into medical costs and non-medical costs. Non-medical costs will consist of formal and informal care costs. Indirect costs, which often form a significant part of the total cost (even in the context of the country under review), represent the Loss of patient and caregiver's productivity returns [51]. (Figure 1).

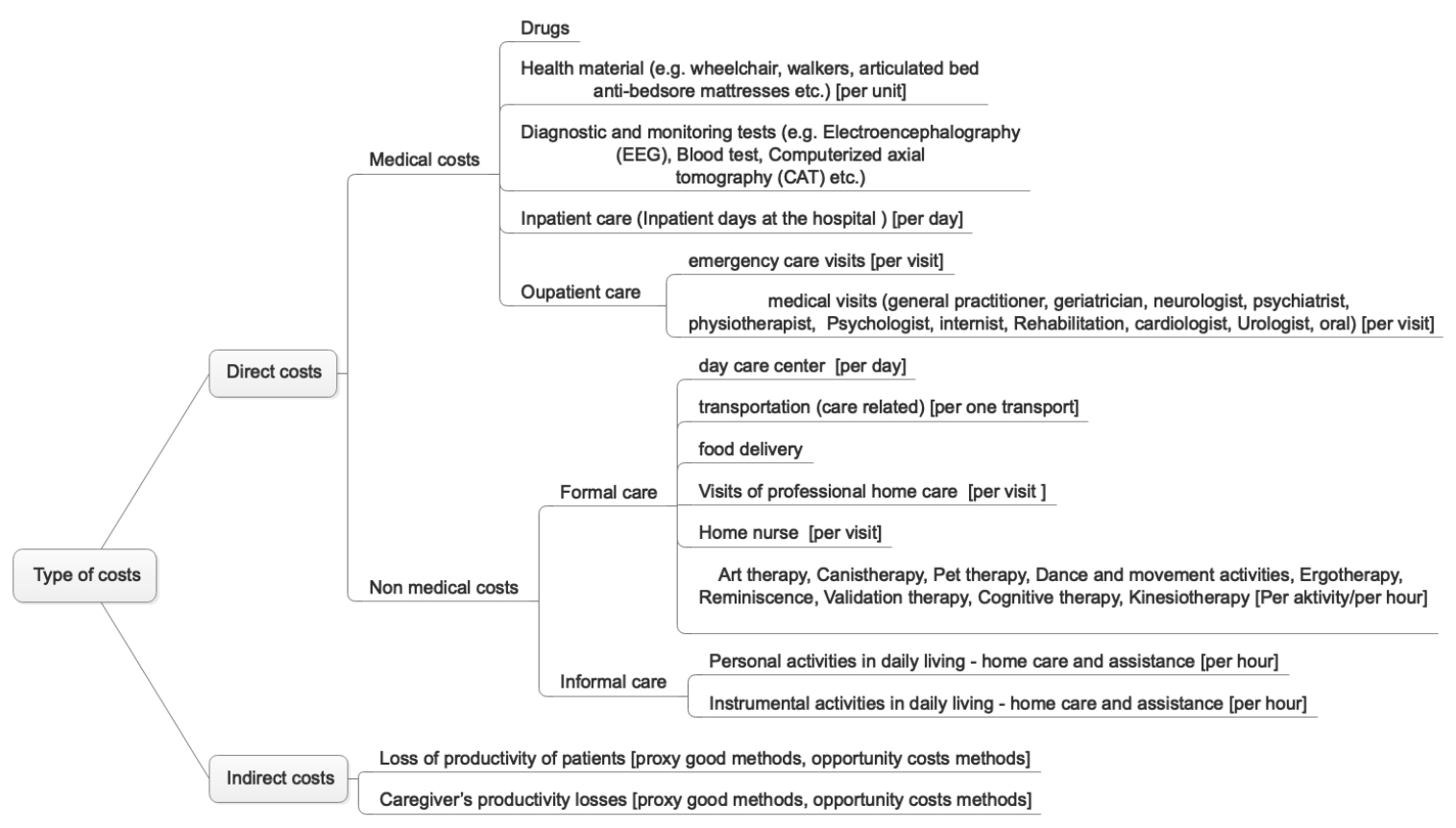

Figure 1. Type of costs (adapted from [51]).

\section{Methodology}

\subsection{Study Design}

This section deals with modeling and data mining and processing. The process of Alzheimer's described in Section 2.1 was abstracted only to those specificities of AD that allocate costs. The resulting model thus represents a process of slowing the progression or easing the patient's daily life. The AD treatment model in this article is defined as a process that typically consists of parallel activities. Deciding which remedy is deployed is then based on a cyclically-performed MMSE test, the score of which is a crucial indicator of disease severity in this work. The essential second attribute for 
process control is the time aspect that is associated with determining the stage of the disease. Remedial measures then also depend on the determination of the disease stage. In the real world, determining the stage and severity of a disease is a complex problem that is based on many soft data and experience. Therefore, time will be the decisive criterion for the transition between stages. Each stage lasts for a specific time that is reflected in the process. Because of the technical limitations of the Software (SW) used (Enterprise Architect), the length of each stage of the disease was fixed. A particular element of coincidence brings in this model the AD drop element. Each time the MMSE test is performed, the MMSE score may decrease. If this decline is substantial, the patient is discontinued from cognitive pharmacological therapy. After the transition to the next phase, cognitive treatment is restarted, and its efficacy is checked. Each phase of AD then has the differently-defined complexity of individual activities. Typically, medicines change along with the progressing disease, and the nature of patient care changes. In the early stages of care, care is directed, as much as possible, to slow the progression of the disease and keep the patient in a regular life regime. In the following stages, care is more focused on minimizing impacts and the quality of life. Most of the activities are also repeated within one phase. Unless otherwise specified in the process, activities are repeated with a monthly period. Typical representatives of events with a different period are medical examinations. If the process used a day-to-month conversion, the month was considered to have 30 days.

The starting point for the determination of costs was the division of $\mathrm{AD}$ into four central units. These units were subsequently broken up into sub-processes as the prices were calculated. Subprocesses were then subdivided into individual sub-activities against which specific costs had already been defined. Determining particular values for individual activities was very difficult, as not all information was directly traceable from public sources. Alternatively, resources vary widely (e.g., an hour of client care). For this reason, those subjects were selected that corresponded to the disintegration of individual processes in the model. Figure 2 shows the flow of the research. The different approaches and methods are presented below.

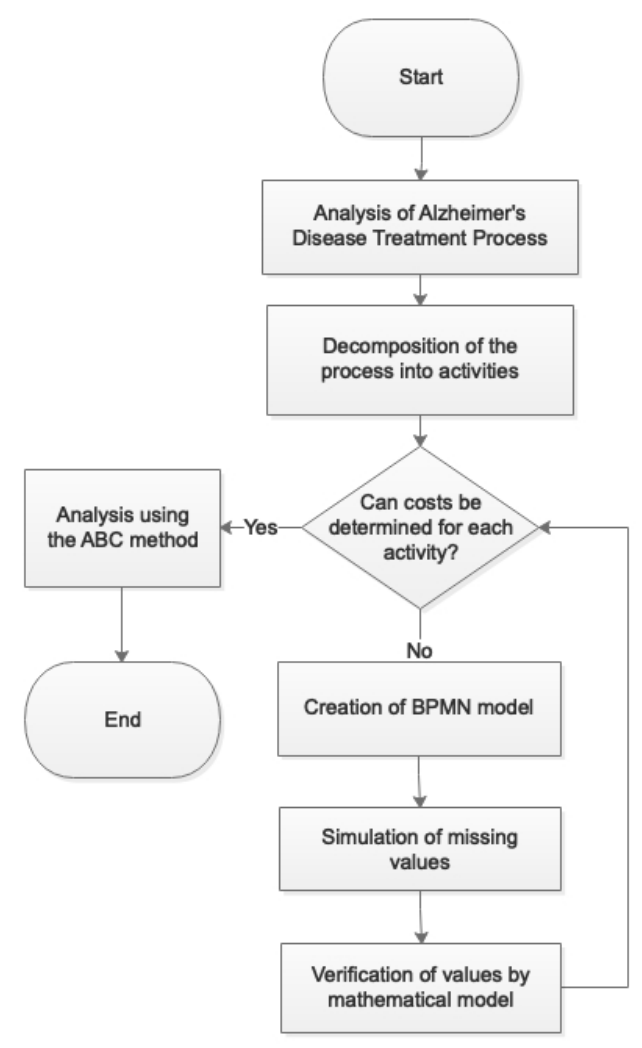

Figure 2. Research flowchart. ABC, Activity-Based Costing. 


\subsection{Modeling Approaches and Methods}

This section presents three basic approaches that have been used to calculate and analyze the cost of caring for patients with Alzheimer's disease.

\subsubsection{Business Process Modeling}

Business Process Model and Notation (BPMN) is not the only standard and tool for modeling business processes. For this article, however, it is suitable. The definition of this tool is as follows: "The Business Process Modeling Notation (BPMN) is a graphical notation that depicts the steps in a business process. BPMN depicts the end-to-end flow of a business process. The notation has been specifically designed to coordinate the sequence of processes and messages flowing between different process participants in a related set of activities" [52].

As follows from the definition, BPMN is a graphical notation that allows capturing the individual process steps. It is specially designed to be able to capture the process as accurately as possible, including all logical patterns and links. It is also intended to be understandable and usable by a wide range of users. Other benefits include its availability in the form of an open standard and a technical foundation in the form of the XML language. This makes it possible to find a wide range of freely-available tools to model BPMN processes.

Processes were created in Sparx Systems Enterprise Architect (EA). However, EA itself does not allow performing a process simulation with data generation and cost calculations. The built-in EA features will enable the simulation of a passage through the process. The BPSim standard will be used to extend simulation options. This standard defines a specification for the parameterization and exchange of process analytic data to allow process capacity analysis and optimization of simulation execution [53].

The BPSim standard was designed with the goal of easy readability by humans; for this reason, just like BPMN, its own data format is implemented in the form of XML outputs.

Descriptions of individual elements can be obtained in the Object Management Group Certified Expert in BPM (OCEB) Certification Manual by [54].

The primary line of the BPMN model is illustrated in Figure 3 when the process is divided into three stages of the disease. It is a simple model because these activities are then broken down to a greater depth. As described earlier for medical BP models, it is necessary to maintain simplicity and clarity for all participants supplying and read information. These models do not expect significant re-engineering, and so, the models are possible to build in depth.

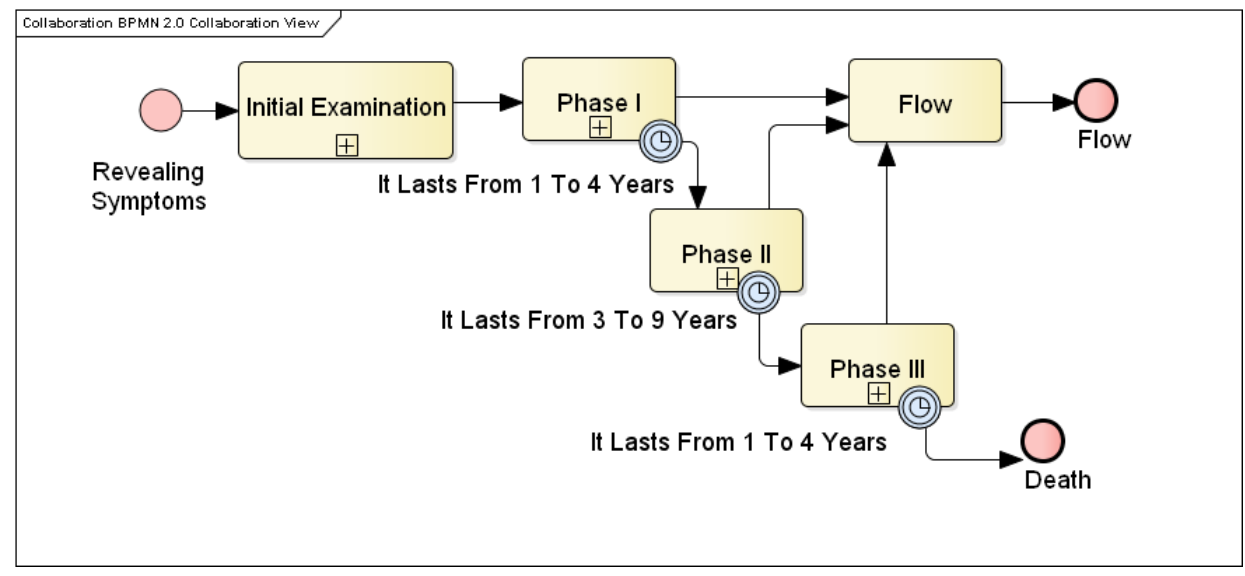

Figure 3. Main layer of the BPMN model.

\subsubsection{Model of System Dynamics}

System dynamics deals mainly with the structure of systems and their behavior. Such a system runs continuously, is not static, and has no beginning or end. Only the structure of the system, 
the existence of its sub-elements, and the relationships between them are permanent. However, the strength of links and the interaction of elements are variable. Individual components and variables respect linear time, and it is possible to monitor their development. Values are constantly changing in response to the passing of time. This is mainly used in quantitative models, where the course of individual variables and their changing values are accurately observed. From the perspective of the whole system, system dynamics considers the time to be cyclical, as the system lasts and "runs constantly". The system itself has no beginning and no end. Only the point at which the system is modeled and observed can be determined.

Based on the results of the study [10], the system dynamics approach was chosen to verify the results of the BPMN simulation quickly. For a system dynamics model of the Alzheimer's disease cost process, a stock and flow diagram was selected in this article. The reason for this choice is above all the fact that in this case, there is not much emphasis on the feedback loop in the system, but above all on the basic modeling of the data and its interrelations. The following sections will describe the basic properties of the stock and flow diagram, its elements, and the tool in which the diagram was modeled.

The software tool used to create a stock and flow diagram in this article was Stella Professional 1.5.1 [55]. Figure 4, showing the primary layer of the mathematical model of the system dynamics, corresponds to the graphical notation of this program, and the built-in features are specific to this solution.

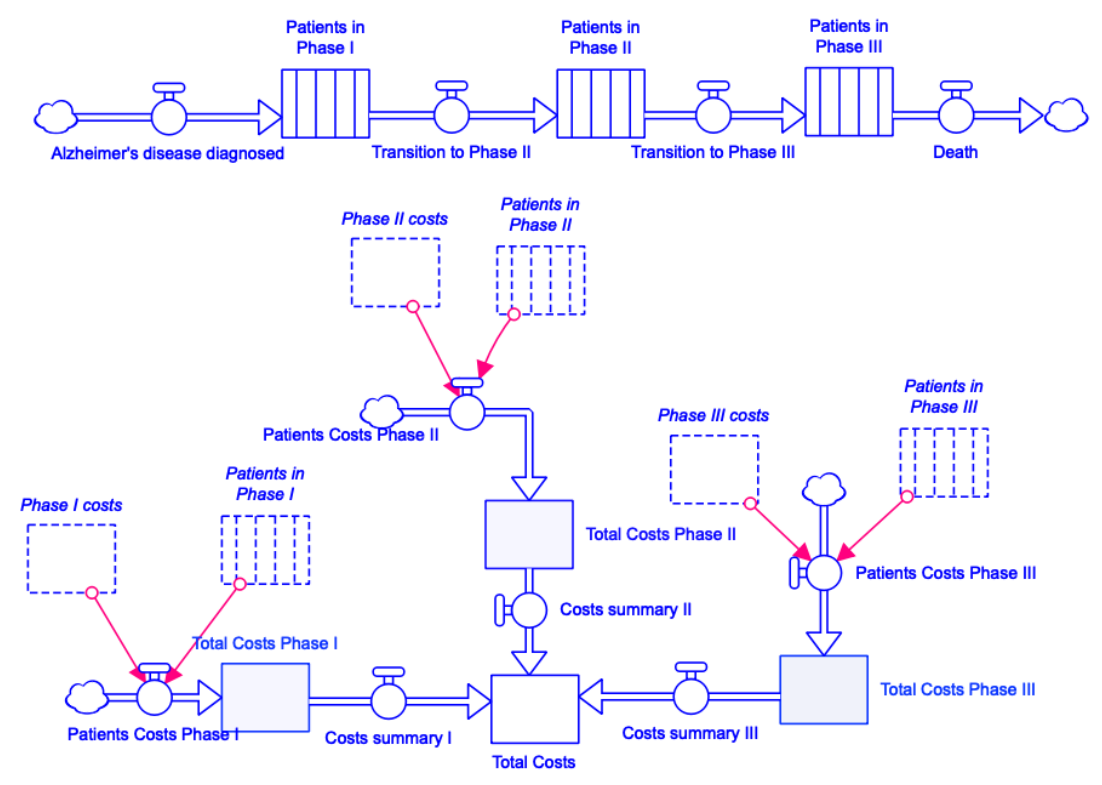

Figure 4. Main layer of the System Dynamics (SD) model.

\subsubsection{Activity-Based Costing}

Activity-Based Costing ( $\mathrm{ABC}$ ) is a part of the $\mathrm{ABC} / \mathrm{ABM}$ (Activity-Based Management) organization process management concept. $\mathrm{ABC}$ provides cost information to determine the cost of all the "components" of an enterprise and to derive the value of the entire process, the resulting product. During ABC analysis, we are not only interested in the size of costs, but above all in the causal relationship between the elements and the relationship between price and emerging values.

Activity-based costing is a costing methodology based on business process management. Product costs are not calculated by centers and strictly divided into direct and indirect costs. The calculation of values is based on the activities to be performed. This methodology is well applicable in areas where classical costing methods are not suitable. 


\subsection{Identification of the AD Main Costs}

The groups were selected following the widely-used cost breakdown, which can be considered as uniform in $\mathrm{AD}$ (Figure 1). From the possible large set of costs, the following cost items, shown in Figure 5, were selected, which also correspond to the standard specification of cost types within other countries [12].

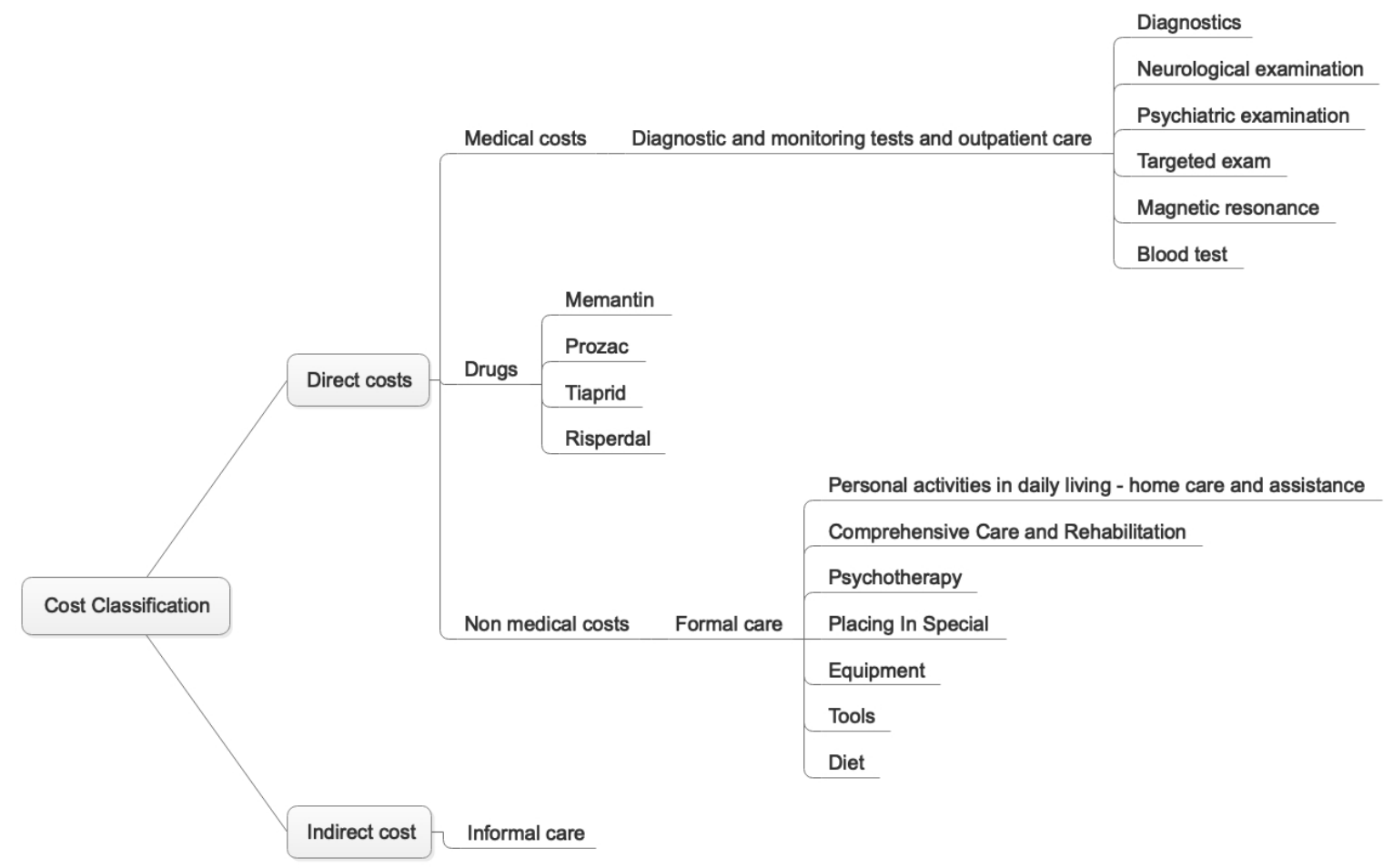

Figure 5. Cost classification.

The costs included in the model were selected under the supervision of a neurologist and based on current Czech legislation, the approaches of Czech health insurance companies, available databases such as the State Institute for Drug Control (SUKL) and the Statistic Office, and analysis of publications on Alzheimer's disease costs in the Czech Republic.

The sources for calculating costs were:

- Previous studies of the same authors that solve partial costs areas (non-pharmacological treatment by [56], health costs by [57], formal and informal care by [58])

- An expert interview with Sunflower Agency's senior staff member, where the cost of assistance services is calculated per hour of work

- Data on direct health costs were updated concerning current prices expressed in the value of points for operations; the source of the data were the records of the largest insurance company in the Czech Republic, General Health Insurance (VZP)

- Expert interviews with a doctor from the Faculty Hospital in Hradec Králové concerning the dosing of drugs in connection with the entry into the model as relevant for variables (Dr. Kuchyňka).

\section{Results}

Many stakeholders are involved in the financing of the treatment and care of Alzheimer's, who often have decision-making powers on the amount of the sickness benefit. These are both private and public entities, which include public health and social care departments of regions and cities, 
which decide on the financing of beds and the creation and financing of capacities in residential facilities, but also for outpatient services. The combination of both health and social care in a single facility (whether social as the home for the elderly) and the follow-up funding make the situation very confusing. This is evidenced by the fact that at present, there is still no unified evidence of costs for AD patients in the Czech Republic or Europe. Figure 6 provides an idea of how financial resources are linked to key players in the context of economic development. In the case of increasing productivity in the economy, the level of GDP is rising, so there is a potential for raising financial resources for health and social care. This, in turn, increases the quality of life not only for the patients themselves, but also for their caregivers, which in turn translates into productivity growth in the system.

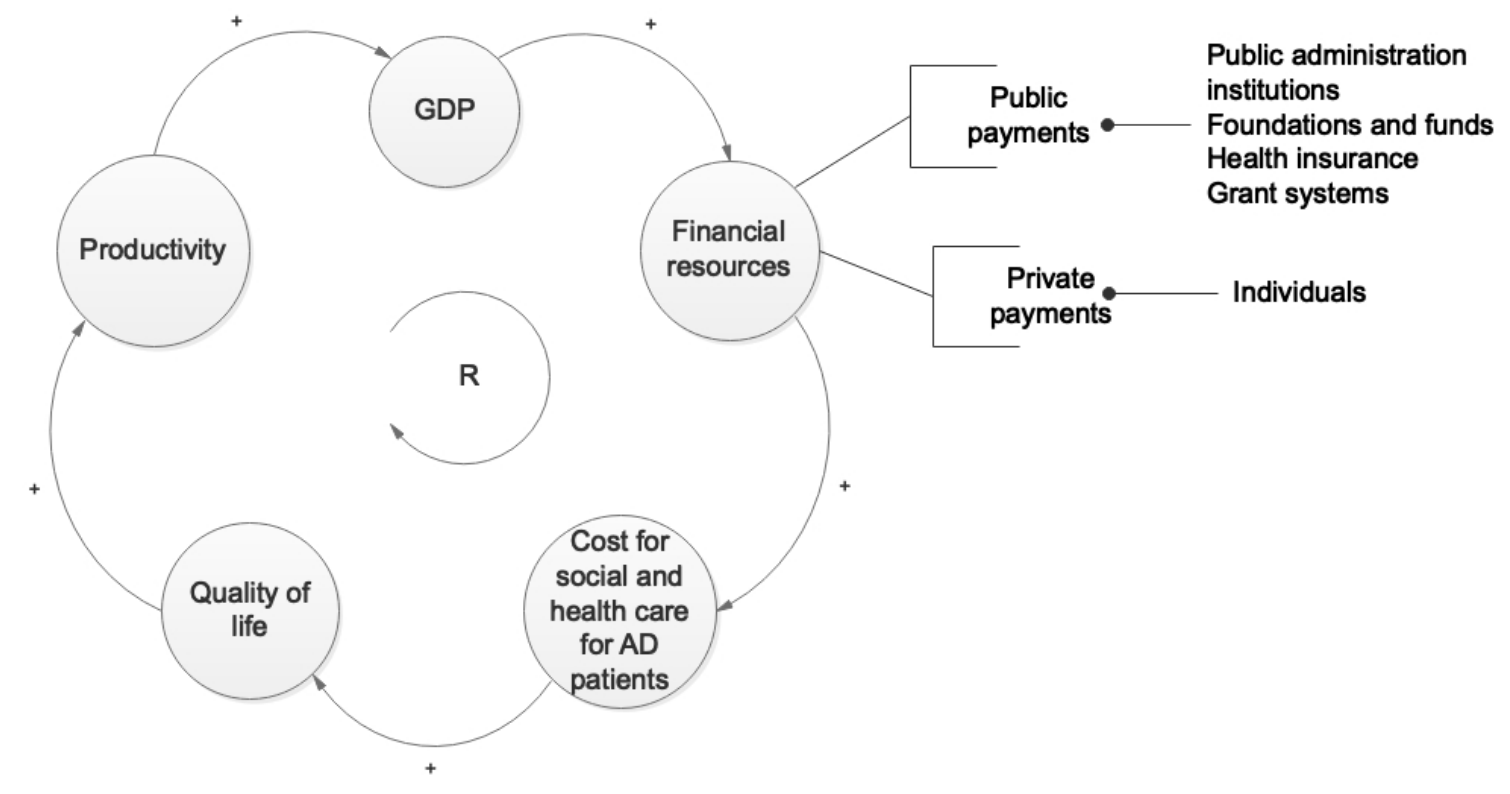

Figure 6. Causality in the health and social system.

The need to declare cost items and their interconnection with financial resources is a fundamental basis for decision-making of competent persons, and the BPMN tool that describes in detail the individual activities is suitable for this purpose.

\subsection{Alzheimer's Disease Cost Model}

The Alzheimer's disease process is, in this section, only focused on those AD components that allocate costs. The resulting process is rather a description and analysis of activities aimed at slowing down the progress of the disease or making the patient's daily life easier. Due to the primary BPMN notation used, Alzheimer's disease treatment can be defined as a process that typically consists of parallel activities. The decision on how the remedy is deployed is then based on a cyclically-performed MMSE test, whose score in this paper is a key indicator of the severity of the disease. The severity of Alzheimer's disease is divided into three stages, as shown below:

- MMSE score $0-10=$ serious illness

- MMSE score 10-20 = moderate

- $\quad$ MMSE score 20-30 = mild

The crucial second attribute for process management is the time point that is related to determining the stage of the disease. The determination of the stage also determines the remedies. In the real world, discovering the stage and severity of the illness is a complex problem that significantly draws from soft data and experience. For this paper, therefore, the decisive criterion for the transition between the stages will be time. Each disease phase takes a certain amount of time that is being considered in the process. 
Due to the technical limitations of Enterprise Architect, the length of each phase of the disease was fixed. A specific element of coincidence in this model is the element of the AD drop. Any MMSE test may cause the MMSE score to drop. When this decrease is high, the pharmacological treatment of cognition is terminated. After the transition to the next phase, cognitive therapy is restarted and its effectiveness controlled. Each of the Alzheimer's disease phases then has a differently defined complexity of individual activities. Typically, medication is changing along with the illness progression, and the nature of patient care changes as well. In the initial stages, attention is focused to the fullest extent possible on slowing down the illness progression and preserving the patient's healthy lifestyle. In the following phases, care is focused more on minimizing the impacts of the disease and retaining the patient's quality of life. This is illustrated, for example, in Figures 7 and 8 . Figure 7 shows patient care activities in the first stage of the disease. This includes activation activities and psychotherapy with the patient. These activities aim to keep the patient mentally active and creative. On the other hand, Figure 8 shows the third phase of AD, where the patient is already entirely dependent on other people, and therefore, care is reduced only to comprehensive medical care as such.

Most activities also take place over one phase repeatedly. Unless otherwise specified in the process, activities were repeated in monthly intervals. Typical representatives of events with a different range are medical examinations. Where the conversion of days to months was used in the process, it was assumed that the month was 30 days.

Remedies for dealing with AD are classified in different ways; the main ones are pharmacological treatment and formal care. Parallel with these activities, regular medical examinations are still carried out. These examinations are intended to monitor the condition of the patient and, if appropriate, to adjust the terms of care or pharmacological treatment. Specialized aids from areas of care for the patient's daily life or therapeutic aids are also included in the care, developing the cognitive and motor functions of the patient. As an alternative to patient care, work is then selected in a specialized facility where it is assumed that all operations are secured directly in the facility and do not generate any additional costs.

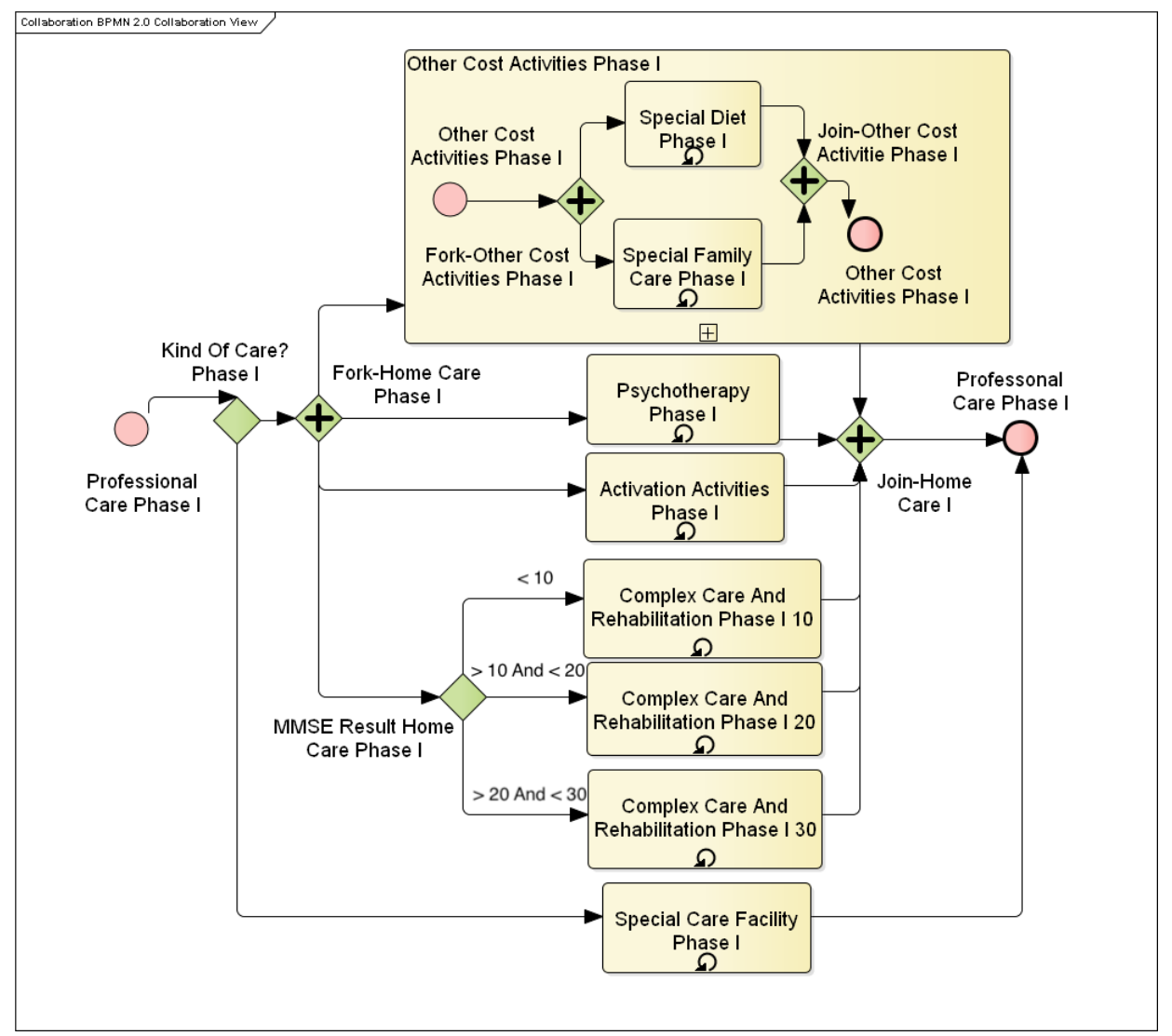

Figure 7. BPMN subprocess of Alzheimer's disease in Phase I. 


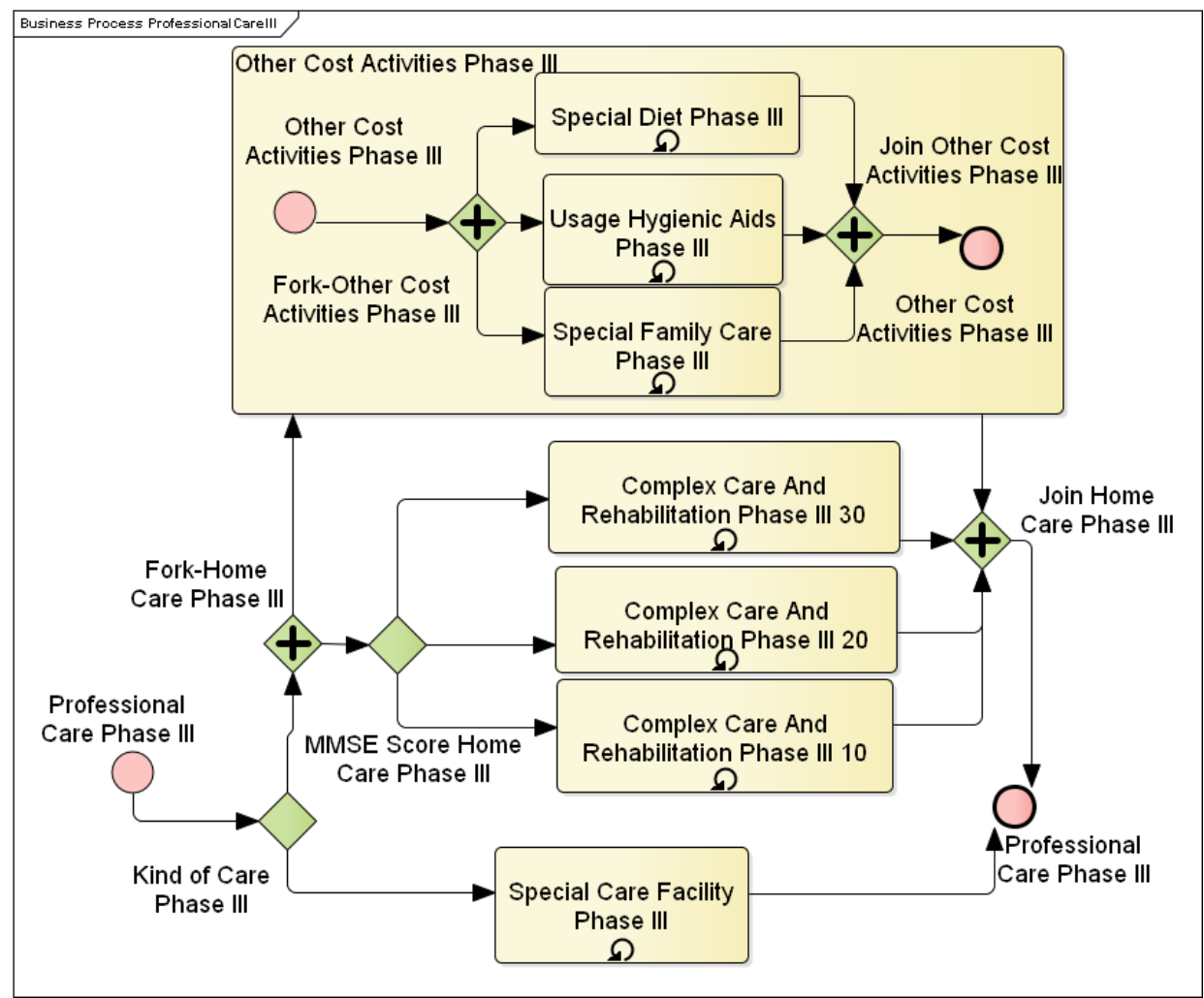

Figure 8. BPMN subprocess of Alzheimer's disease in Phase III.

\subsection{Alzheimer's Disease Cost Calculation}

For the individual activities described in the previous section, it was necessary to assign cost variables and their units. For the whole model, the Czech crown was used as the currency, mainly due to the use of current prices in online resources such as the State Institute for Drug Control and, where appropriate, price-lists of care services or homes. Quantities taken from research and articles where they were denominated in euros were translated at the current exchange rate. This conversion caused values to be distorted, but this was not a significant issue in terms of the calculation mechanism. The outputs referred to in this article were then converted and denominated in euros.

Medical performances were valued based on the point value of individual actions. Each operation had a certain number of points indicating the intensity of the activity, and one point had its value in crowns. Given that Decree No. 134/1998 Coll. is very complex and in order to arrive at the real point value, it was necessary to combine several tasks at once, and the point evaluation of individual acts was taken from the article [57].

The cost of pharmaceutical treatment was based on the recommended dosage of medication per day. The dosing was then compared to the indicated package size and package prices stated on the website of the State Institute for Drug Control [42] in the "Indicative Selling Price" box.

To define the cost of care, the primary source of the public price list was the Sunflower and Home at the Fountain website. The Sunflower Agency provides specialized patient care at home, and Fountain Home is a dedicated facility for seniors and people living with dementia. A partial source for the definition of care costs was [56], which presented the prices of musical therapy and activation activities.

A specific area for costing was the cost of tools, meals, or increased family care. To determine the price of food, Decree 505/2006 Coll. was used. The value of the maximum amount of reimbursement for the provision of care services and the like according to the VZP Payment Card was used for the determination of the cost of hygiene aids. The cost of increased family care was calculated as the 
cost of the sacrificial opportunity, taking into account the average wage in the Czech Republic. Assay calculations were based on published research in the thesis [59].

The starting point for determining costs was to divide Alzheimer's disease into a total of four central units. These units were then submerged into subprocesses, depending on how the cost would be calculated. The subprocesses were then broken down into individual sub-activities for which specific costs had already been defined. The following sections describe the unique activities and assign numerical cost values to them.

Identifying specific values for individual activities was very difficult, as not all information was directly traceable from public sources. Alternatively, resources vary greatly (e.g., client care hours). For this reason, the subjects were chosen in the article, and their level of appreciation corresponded to the breakdown of individual processes in this article.

\subsubsection{Cost of Alzheimer's Disease Diagnostics}

The subprocess only occurred once in the process. Given that this subprocess had just one occurrence in the model, at the beginning of the model, it was decided to treat it as a separate unit. The cost of this subprocess consisted of medical examinations of a patient suspected of having AD. Each exam had a point value [57]. The exam fee was then determined by multiplying this point value and point price. The point price was taken from the Ministry of Health's response [60], where the value of one point was approximately $0.02 €$. The costs of individual actions are shown in Table 1.

Table 1. Cost of medical examinations.

\begin{tabular}{lcc}
\hline Medical Operation & Spot Value & Price \\
\hline Neurological examination & 790 & $16.97 €$ \\
Psychiatric examination & 241 & $5.20 €$ \\
Targeted exam: MMSE test & 939 & $20.16 €$ \\
Magnetic resonance & 2155 & $46.29 €$ \\
Blood test & 396 & $8.52 €$ \\
\hline
\end{tabular}

\subsubsection{Costs of Pharmacological Treatment}

Costs of pharmacological treatment included repeatedly occurring subprocesses from each of the three phases of the disease. Some medications are always administered, regardless of the severity of Alzheimer's disease. Other drugs are only given at a certain hardness of the disease or only at a specific trend of disease development. Specifically, this applies to donepezil, which is only used for moderate Alzheimer's disease.

Where more possible drugs could be chosen from available sources and it was not possible to simulate their combination (e.g., substitution for poor drug tolerance), the most commonly-used drug was chosen. A similar approach was used if only the active substance were mentioned in the article, and several drugs could be traced under different brand names.

Assignment of drug groups to the different stages of the disease was based on consultations with MUDr. Jiř́ Kuchyňka, and only specific names of drugs and their prices were sought; see Table 2.

- Donepezil: This is an active substance that is represented by a drug with the marketing name Aricept. This medicine is intended for patients with an MMSE score higher than 20. This medicine belongs to the cognitive group.

- Memantine: This is another cognitive drug intended for patients with an MMSE score of fewer than 20 points. The name of the active substance is the same as the name of the medicine. For both of these drugs, it is common that the effectiveness of the treatment is evaluated every three months. When the treatment is not effective, drug administration is discontinued.

- Prozac: This is an antidepressant administered in all three phases of the disease to alleviate the effects of depressive states. In the modeled process, it is still prescribed at the same dose. 
- Tiapride: This is a neuroleptic/antipsychotic drug for the second stage of Alzheimer's disease. During the entire second phase, it is administered as a single dose.

- Risperdal: This is a neuroleptic/antipsychotic drug for the third phase of Alzheimer's disease. During the entire third phase, it is administered as a single dose.

Table 2. Cost of medicines.

\begin{tabular}{lccc}
\hline Drugs Name & Dosage & Price Per Pack & Price Per Month \\
\hline Donepezil & $10 \mathrm{mg} /$ day & $374.22 € / 98$ dosage & $121.09 €$ \\
Memantine & $20 \mathrm{mg} /$ day & $29.03 € / 30$ dosage & $29.03 €$ \\
Prozac & $20 \mathrm{mg} /$ day & $13.16 € / 30$ dosage & $13.28 €$ \\
Tiapride & $5 \mathrm{tablet} /$ day & $11.72 € / 50$ tablet & $35.16 €$ \\
Risperdal & $4 \mathrm{mg} /$ day & $21.48 € / 20$ dosage & $32.23 €$ \\
\hline
\end{tabular}

\subsubsection{Formal Care}

This subprocess reappears in each of the three phases of the disease. In terms of patient care, two different approaches are possible, which will be reflected in the cost calculation. The first is patient care in the place of the patient's residence. In this case, all care items must be calculated individually, including extra costs for "material". The material covers hygienic and therapeutic aids and catering costs. The concept of care includes activities that are carried out by specialized personnel. These involve various therapies and activation activities. It also covers general comprehensive care and mobility-based exercises provided by an assistance service at the place of residence to compensate for the patient's inability to perform normal activities. For example, this includes assistance with dressing, and so on. Specific in this care is the cost arising from the need for the family to provide increased attention to the patient.

The cost of assistance services was calculated per hour of work. The price list of the Sunflower Agency was used for pricing, and regular care for seniors was expected at an hourly rate of $6.25 €$. The cost of activation activities was taken from the article [56], where the values were given per month. The price of psychotherapy was determined based on a price list on the Internet, and two psychiatric visits per month were expected.

The number of hours spent on patient care was obtained from the diploma thesis [59], where the average values for formal and informal care and the severity of illness were stated. This article assumed that care was divided equally between the assistance service and the family. The value of the care provided by the assistance service was further adjusted according to the stage of the illness. It was assumed that a patient in the first stage will require less care than a patient in the last stage. Family care was supposed to be the same throughout the illness.

The exact calculations are shown in Tables 3 and 4.

Table 3. Day care hours.

\begin{tabular}{lc}
\hline MMSE Score & Day Care Hours \\
\hline MMSE $0-10$ & 17.3 \\
MMSE $10-20$ & 13.7 \\
MMSE $20-30$ & 12 \\
\hline
\end{tabular}


Table 4. Complex care and rehabilitation costs

\begin{tabular}{ccccc}
\hline & MMSE & Hours Per Day & Hours Per Month & Cost Per Month \\
\hline Phase I & $0-10 \mathrm{pts}$ & 3 & 90 & $562.50 €$ \\
& $10-20 \mathrm{pts}$ & 2.3 & 70 & $437.50 €$ \\
& $20-30 \mathrm{pts}$ & 2 & 60 & $375.00 €$ \\
\hline \multirow{2}{*}{ Phase II } & $0-10 \mathrm{pts}$ & 4.5 & 135 & $843.75 €$ \\
& $10-20 \mathrm{pts}$ & 3.5 & 105 & $656.25 €$ \\
& $20-30 \mathrm{pts}$ & 3 & 90 & $562.50 €$ \\
\hline \multirow{2}{*}{ Phase III } & $0-10 \mathrm{pts}$ & 9 & 270 & $1687.50 €$ \\
& $10-20 \mathrm{pts}$ & 7 & 210 & $1312.50 €$ \\
& $20-30 \mathrm{pts}$ & 6 & 180 & $1125.00 €$ \\
\hline
\end{tabular}

The last kind of formal care was the placement of the patient in a home for the elderly. In the calculation, the price list of Home at the Fountain was used. Placement costs included payment for accommodation in a single-occupancy room with five meals per day. Besides, the cost of care was calculated as a cost depending on the degree of dementia. The models then used the total price per month. The exact calculation is shown in Table 5.

Table 5. Placement costs in a specialized institution.

\begin{tabular}{lc}
\hline & Monthly Costs \\
\hline Phase I & $455.86 €$ \\
Phase II & $772.27 €$ \\
Phase III & $942.19 €$ \\
\hline
\end{tabular}

\subsubsection{Other Expenditure Activities}

This subprocess was linked to activities that generate costs associated with formal and informal care at home, but the nature of these activities cannot be included in formal care. Other costs are specific to each stage of the disease, and where activities are repeated at different stages, they can be valued at different rates. Table 6 shows the cost valued into various stages of the disease.

Another specific feature of this subprocess is that each activity was valued differently. Material aids in this subprocess were evaluated based on the Methodology for VZP Medical Devices. This methodology specifies a group of incontinence aids, indicating the maximum amount of reimbursement based on the severity of the disease.

Caregivers are also included in this category. For the sake of simplicity, it was valued hourly, and one hour of the family member's work was recalculated from the average Czech wage. According to the Czech Statistical Office, the average gross salary in the fourth quarter of 2017 was $1236.41 €$. The average gross hourly wage was determined as a gross wage divided by 160 , i.e., $7.7 €$ per hour after rounding.

The food costs in this paper were based on Decree 505/2006 Coll., which sets the maximum amount of food costs. For this paper, only lunch was calculated in the first phase, while in the second and third stages, full-day meals were calculated. The price of one lunch was set at $3 €$, and full-day meals cost $6.6 €$.

The cost of providing special tools was taken from the diploma thesis $[59,61]$, which showed the average price per month for medical aids. Costs were differentiated according to the severity of the disease. The value of rehabilitation aids was derived from this amount. 
Table 6. ABC; cost resource pools in $€$.

\begin{tabular}{lrrrr}
\hline & Total Cost & Phase I & Phase II & Phase III \\
\hline Pharmacological treatment & $920,539.84$ & $127,923.44$ & $583,026.56$ & $209,589.84$ \\
Medical care & $113,957.03$ & $27,535.16$ & $61,773.44$ & $24,648.44$ \\
Care & $15,436,858.20$ & $3,126,016.25$ & $8,037,072.42$ & $4,273,769.53$ \\
Other expenditure activities & $8,131,287.11$ & 0 & $4,732,771.48$ & $3,398,515.63$ \\
Initial examination & 9703.13 & 0 & 0 & 0 \\
\hline
\end{tabular}

In Table 7, the number of units entered in the BPMN simulation and activity costs were entered. Subsequently, the total cost was divided by the number of units, and unit costs were obtained that matched the costs entered into the EA simulation engine.

Table 7. ABC: check-table of all costs.

\begin{tabular}{lrrr}
\hline & Units & Costs & Costs \\
\hline Risperdal & 4100 & $32.23 €$ & $132,128.91 €$ \\
Memantine & 3500 & $87.89 €$ & $307,617.19 €$ \\
Prozac & 7348 & $13.28 €$ & $97,590.63 €$ \\
Tiapride & 10,900 & $35.16 €$ & $383,203.13 €$ \\
Examination of cerebrospinal fluid & 1700 & $19.61 €$ & $33,335.94 €$ \\
Blood tests & 2900 & $8.48 €$ & $24,582.03 €$ \\
MMSE Test & 4900 & $5.47 €$ & $26,812.50 €$ \\
Examination by a neurologist & 2900 & $10.08 €$ & $29,226.56 €$ \\
Comprehensive care and rehabilitation & 9574 & $741.91 €$ & $7,103,031.25 €$ \\
Psychotherapy & 5760 & $41.72 €$ & $240,300.00 €$ \\
Placing in special equipment & 10,326 & $772.27 €$ & $7,974,414.84 €$ \\
Tools & 17,419 & $38.95 €$ & $678,450.39 €$ \\
Diet & 7173 & $199.22 €$ & $1,428,996.09 €$ \\
Family care & 7173 & $839.80 €$ & $6,023,840.63 €$ \\
\hline Total & & & $24,483,530.08 €$ \\
\hline
\end{tabular}

\section{Discussion}

Our BPMN simulation was performed for 100 passes through a fixed-length phase process. The duration of each phase was set at 48,108 , and 40 months. Furthermore, decisions were made about home care or placement in a specialized facility. This decision was made again for each phase, and the probability of home care was set to 0.5 for simulation purposes. Half of the patients were treated at home and half in a specialized facility. Five simulations were set up, and each MMSE score set, which affected the passage through the process.

The following Table 8 shows the average cost per patient and month of treatment based on the MMSE score setting. In SD simulations, the home care flag and MMSE score were manually switched. Consequently, the simulation was performed for constant MMSE score values for the home and facility options, and the resulting value was determined as the average of the two surveys.

Table 8. Average cost per person/month according to the models.

\begin{tabular}{lcc}
\hline MMSE Score & Avg. Cost (BPMN) & Avg. Cost (SD) \\
\hline MMSE 5 & $1335.43 €$ & $1632.81 €$ \\
MMSE 15 & $1206.48 €$ & $1105.47 €$ \\
MMSE 25 & $1054.53 €$ & $851.56 €$ \\
Normal distribution $(0-30)$ & $1198.05 €$ & \\
Mean & & $1196.60 €$ \\
\hline
\end{tabular}

Unfortunately, it is not possible to compare the BPMN and SD model with reality, and there are only other estimates based on the sample; in the Czech Republic, it is for example [62]. In comparison 
with this study, the BPMN value of direct costs in mild dementia was closer to this study (in [62] 1241.2 (1437.3)); in our BMPN study it showed $1331.26 €$, and SD showed $1627.72 €$. It is not possible to deduce the accuracy of the BPMN and SD approaches.

In the health sector, there are various legal constraints and treatment guidelines that professionals need to follow, so the regular use of business process reengineering (i.e., the introduction of radical changes and new procedures) is not recommended here. Publication [63] stated that less radical Business Process Management (BPM) principles are needed in health care $[64,65]$. Thus, short and accurate processes and continuous improvement are feasible, depending on the restrictive environment and legal prerequisites. Using partial iterations, you can optimize the process, i.e., reduce costs, relieve employees from routine work, and improve patient safety, without the need to innovate the entire company.

In other studies in this field, process analyses from costs were usually concerned only with the area of cost pricing in an enterprise [66-68]. For example, publications [69-71] are valued in health care. However, these contributions were focused on time-driven ABC. Therefore, they are based only on time consumed by the activity and the appreciation of that time. A comprehensive view of indirect costs is still lacking. Business process simulation is mostly concerned with simulating hard processes. The authors assumed that all the information was available, and the simulation was performed first at the As-Is level (with the current data) of the process, then changes were made to the To-Be (future status analysis), and the assumption was that there were no changes in the process [72-75]. Other relevant studies utilized the Markov model for a simulation of the patient's progress through several stages, which took into account the stage of the disease and differentiated between patients treated at home and institutionalized patients. One paper by [76] employed the Markov model for simulating the progress of the disease in the population. The paper [77] focused on the entire population versus the group of dementia patients and studied the relationships between hospitalizations and mortality, using logistic and Cox regression models. Finally, the paper [78] illustrated that given the complexity of the subject, it was complicated to arrive at an accurate prediction of the relationship between treatment efficacy and costs in the long term.

What the research studies conducted so far had in common, no matter their chosen simulation method and data projections, was that there was a lack of reliable data to capture the process of this complex disease in its entirety. Since the number of Alzheimer's disease patients is rising and so are the costs associated with their treatment, it is vital to encourage collaborative research allowing access to a more significant amount of quality data in order to explore more fully the potential impact of new treatment methods and medications on the cost-effectiveness of processes in this field.

\section{Conclusions}

For the models mentioned here, the key is how the costs of individual operations are determined and what actions are included in the cost calculation. Another critical factor influencing the costs is the duration of the illness. The total costs on the care for Alzheimer's disease patients are the sum of direct and indirect costs. The results of this study were in keeping with the conclusions made by similar studies, that is the costs of Alzheimer's disease increase with the severity of the disease and the decline of the patient into later stages of the disease. The results were based on the selection of original data, and at the same time, this model pointed to the processes and subprocesses that led to the costs. On this basis, it is possible to clearly and without duplication see the separation of social and health care, as well as the individual outcomes within this care and the link to the stage of the disease, which is often crucial knowledge for persons in the management functions of public administration and self-government in the area of finance and management not in the field of specific diseases.

The presence of indirect costs further complicates the situation. Indirect costs account for the majority of total costs and are at present calculated by the use of the opportunity or proxcost methods. They are dependent on the economic condition of the given country, average wages, and, indirectly, on the GDP. Because of this fact, it is impossible to use indirect costs calculated for one country in 
another country without distorting the results significantly. Indirect costs vary greatly not only among the continents, such as Europe and America, but also among the countries in Europe. However, knowing the volume of indirect costs and, above all, the closure and the type of care that arises, the theoretic proctor seeks solutions to be gradually reduced in the future.

Knowing the needs of treatment and care within one of the most society-burdening diseases will enable society in the Czech Republic and elsewhere to be better equipped to face these challenges when a substantial body of local evidence is gathered and regularly updated.

Author Contributions: H.T. and M.K. processed the modeling section and P.M. and M.K. processed the economic part of the article. The share of publishing was equivalent.

Funding: The work was supported by the Ministry of Education, Youth and Sports of the Czech Republic (Project ERDF No. CZ.02.1.01/0.0/0.0/18_069/0010054)

Acknowledgments: The authors would like to thanks Jiří Kuchyňka, neurologist at the Faculty Hospital of Hradec Králové, for AD information consultations.

Conflicts of Interest: The authors declare no conflict of interest.

\section{References}

1. Committee on Quality of Health Care in America; Institute of Medicine Staff. Crossing the Quality Chasm: A New Health System for the 21st Century; National Academies Press: Washington, DC, USA, 2001.

2. DiMasi, J.A.; Hansen, R.W.; Grabowski, H.G. The price of innovation: New estimates of drug development costs. J. Health Econ. 2003, 22, 151-185. [CrossRef]

3. Hill, T. The Innovative Use of Process Management in Global Healthcare. 2018. https://www.signavio. com/post/process-management-in-global-healthcare/ (accessed on 15 August 2019).

4. Beckmann, N.; Schuler, A.; Mueggler, T.; Meyer, E.P.; Wiederhold, K.H.; Staufenbiel, M.; Krucker, T. Age-dependent cerebrovascular abnormalities and blood flow disturbances in APP23 mice modeling Alzheimer's disease. J. Neurosci. 2003, 23, 8453-8459. [CrossRef] [PubMed]

5. Jack, C.R., Jr.; Holtzman, D.M. Biomarker modeling of Alzheimer's disease. Neuron 2013, 80, 1347-1358. [CrossRef] [PubMed]

6. Kondo, T.; Asai, M.; Tsukita, K.; Kutoku, Y.; Ohsawa, Y.; Sunada, Y.; Imamura, K.; Egawa, N.; Yahata, N.; Okita, K.; et al. Modeling Alzheimer's disease with iPSCs reveals stress phenotypes associated with intracellular $A \beta$ and differential drug responsiveness. Cell Stem Cell 2013, 12, 487-496. [CrossRef] [PubMed]

7. McGowan, E.; Eriksen, J.; Hutton, M. A decade of modeling Alzheimer's disease in transgenic mice. TRENDS Genet. 2006, 22, 281-289. [CrossRef] [PubMed]

8. Brookmeyer, R.; Gray, S.; Kawas, C. Projections of Alzheimer's disease in the United States and the public health impact of delaying disease onset. Am. J. Public Health 1998, 88, 1337-1342. [CrossRef] [PubMed]

9. Brookmeyer, R.; Johnson, E.; Ziegler-Graham, K.; Arrighi, H.M. Forecasting the global burden of Alzheimer's disease. Alzheimer's Dement. 2007, 3, 186-191. [CrossRef] [PubMed]

10. Cimler, R.; Tomaskova, H.; Kuhnova, J.; Dolezal, O.; Pscheidl, P.; Kuca, K. Numeric, Agent-based or System dynamics model? Which modeling approach is the best for vast population simulation? Curr. Alzheimer Res. 2018, 15, 789-797. [CrossRef] [PubMed]

11. Ferri, C.P.; Prince, M.; Brayne, C.; Brodaty, H.; Fratiglioni, L.; Ganguli, M.; Hall, K.; Hasegawa, K.; Hendrie, H.; Huang, Y.; et al. Global prevalence of dementia: A Delphi consensus study. Lancet 2005, 366, 2112-2117. [CrossRef]

12. Prince, M.; Bryce, R.; Albanese, E.; Wimo, A.; Ribeiro, W.; Ferri, C.P. The global prevalence of dementia: A systematic review and metaanalysis. Alzheimer's Dement. 2013, 9, 63-75. [CrossRef]

13. Sosa-Ortiz, A.L.; Acosta-Castillo, I.; Prince, M.J. Epidemiology of dementias and Alzheimer's disease. Arch. Med. Res. 2012, 43, 600-608. [CrossRef] [PubMed]

14. Tomaskova, H.; Kuhnova, J.; Cimler, R.; Dolezal, O.; Kuca, K. Prediction of population with alzheimer's disease in the european Union using a system dynamics model. Neuropsychiatr. Dis. Treat. 2016, 12, 1589. [PubMed]

15. Bond, M.; Rogers, G.; Peters, J.; Anderson, R.; Hoyle, M.; Miners, A.; Moxham, T.; Davis, S.; Thokala, P.; Wailoo, A.; et al. The effectiveness and cost-effectiveness of donepezil, galantamine, rivastigmine and 
memantine for the treatment of Alzheimer's disease (review of Technology Appraisal No. 111): A systematic review and economic model. Health Technol. Assess. 2012, 16. [CrossRef] [PubMed]

16. Jönsson, L.; Lindgren, P.; Wimo, A.; Jönsson, B.; Winblad, B. The cost-effectiveness of donepezil therapy in Swedish patients with Alzheimer's disease: A Markov model. Clin. Ther. 1999, 21, 1230-1240. [CrossRef]

17. Loveman, E.; Green, C.; Kirby, J.; Takeda, A.; Picot, J.; Payne, E.; Clegg, A. The clinical and cost-effectiveness of donepezil, rivastigmine, galantamine and memantine for Alzheimer's disease. Health Technol. Assess. 2006, 10, 1-176. [CrossRef]

18. Maresova, P.; Tomaskova, H.; Kuca, K. The use of simulation modelling in the analysis of the economic aspects of diseases in old age. In Business Challenges in the Changing Economic Landscape-Vol. 1; Springer: Berlin, Germany, 2016; pp. 369-377.

19. Green, C.; Shearer, J.; Ritchie, C.W.; Zajicek, J.P. Model-based economic evaluation in Alzheimer's disease: A review of the methods available to model Alzheimer's disease progression. Value Health 2011, 14, 621-630. [CrossRef] [PubMed]

20. Anderson, R.; Knapp, M.; Wittenberg, R.; Handels, R.; Schott, J.M. Economic Modelling of Disease-Modifying Therapies in Alzheimer's Disease. Ph.D. Thesis, Institute of Neurology, London, UK, 2018.

21. Getsios, D.; Blume, S.; Ishak, K.J.; Maclaine, G.; Hernández, L. An economic evaluation of early assessment for Alzheimer's disease in the United Kingdom. Alzheimer's Dement. 2012, 8, 22-30. [CrossRef] [PubMed]

22. Wolstenholme, E.; Monk, D.; Smith, G.; McKelvie, D. Using system dynamics to influence and interpret health and social care policy in the UK. In Proceedings of the System Dynamics Conference, Oxford, UK, 25-29 July 2004.

23. Sterman, J. System Dynamics: Systems Thinking and Modeling for a Complex World; Massachusetts Institute of Technology, Engineering Systems Division: Cambridge, MA, USA, 2002.

24. Hirsch, G.; Homer, J.; McDonnell, G.; Milstein, B. Achieving health care reform in the United States: Toward a whole-system understanding. In Proceedings of the 23rd International Conference of the System Dynamics Society, Boston, MA, USA, 17-21 July 2005; pp. 17-21.

25. Grimm, V.; Berger, U.; Bastiansen, F.; Eliassen, S.; Ginot, V.; Giske, J.; Goss-Custard, J.; Grand, T.; Heinz, S.K.; Huse, G.; et al. A standard protocol for describing individual-based and agent-based models. Ecol. Model. 2006, 198, 115-126. [CrossRef]

26. Bonabeau, E. Agent-based modeling: Methods and techniques for simulating human systems. Proc. Natl. Acad. Sci. USA 2002, 99, 7280-7287. [CrossRef] [PubMed]

27. Goldberg, D.E.; Holland, J.H. Genetic algorithms and machine learning. Mach. Learn. 1988, 3, 95-99. [CrossRef]

28. Koza, J.R.; Koza, J.R. Genetic Programming: On the Programming of Computers by Means of Natural Selection; MIT Press: Cambridge, MA, USA, 1992; Volume 1.

29. Back, T. Evolutionary Algorithms in Theory and Practice: Evolution Strategies, Evolutionary Programming, Genetic Algorithms; Oxford University Press: Oxford, UK, 1996.

30. Gantt, J.A.; Gatzke, E.P. A stochastic technique for multidimensional granulation modeling. AIChE J. 2006, 52, 3067-3077. [CrossRef]

31. Immanuel, C.D.; Doyle, F.J., III. Solution technique for a multi-dimensional population balance model describing granulation processes. Powder Technol. 2005, 156, 213-225. [CrossRef]

32. Poon, J.M.H.; Ramachandran, R.; Sanders, C.F.; Glaser, T.; Immanuel, C.D.; Doyle, F.J., III; Litster, J.D.; Stepanek, F.; Wang, F.Y; Cameron, I.T. Experimental validation studies on a multi-dimensional and multi-scale population balance model of batch granulation. Chem. Eng. Sci. 2009, 64, 775-786. [CrossRef]

33. Lubarsky, D.A.; Glass, P.S.; Ginsberg, B.; de Dear, G.L.; Dentz, M.E.; Gan, T.J.; Sanderson, I.C.; Mythen, M.G.; Dufore, S.; Pressley, C.C.; et al. The Successful Implementation of Pharmaceutical Practice Guidelines Analysis of Associated Outcomes and Cost Savings. Anesthesiol. J. Am. Soc. Anesthesiol. 1997, 86, 1145-1160.

34. Andellini, M.; Riesgo, S.F.; Morolli, F.; Ritrovato, M.; Cosoli, P.; Petruzzellis, S.; Rosso, N. Experimental application of Business Process Management technology to manage clinical pathways: A pediatric kidney transplantation follow up case. BMC Med. Inform. Decis. Mak. 2017, 17, 151. [CrossRef] [PubMed]

35. Panella, M.; Marchisio, S.; Di Stanislao, F. Reducing clinical variations with clinical pathways: Do pathways work? Int. J. Qual. Health Care 2003, 15, 509-521. [CrossRef] [PubMed]

36. Schmidt, D. Alzheimercentrum. 2000. Available online: https://www.alzheimercentrum.cz/ (accessed on 10 October 2017). 
37. Czech Alzheimers Society. Czech Alzheimers Society, o.p.s. 2015. Available online: http://www.alzheimer. $\mathrm{cz} /$ (accessed on 8 November 2017).

38. Ressner, P. Alzheimer's Disease-Diagnosis and Treatment. 2004. Available online: http:/ / www.neurologiepropraxi.cz/pdfs/neu/2004/01/04.pdf (accessed on 19 February 2018).

39. Jirak, R. Diagnosis and Therapy of Alzheimer Diseases. 2008. Available online: https://www. neurologiepropraxi.cz/pdfs/neu/2008/04/10.pdf (accessed on 19 February 2018).

40. Mlcochova, E. Symptoms, Manifestations. 2012. Available online: http://www.priznaky-projevy.cz/ (accessed on 18 February 2019).

41. Polach, L. Cognitive and Nootropic. 2016. Available online: http://www.upsychiatra.cz/kognitiva-anootropika/ (accessed on 19 February 2019).

42. State Institute for Drug Control, State Institute for Drug Control. 2018. Available online: http://www.sukl. $\mathrm{cz} /$ (accessed on 12 October 2018).

43. Soltesova, J. Care of Men with Dementia (Alzheimer's Disease)—Comparison Home and Institutional Care of Client (South Bohemia Region). Bachelor's Thesis, University of South Bohemia in České Budějovice, Pedagogical Fakulty, České Budějovice, 2012.

44. Halova, J. Activation Activities for People with Alzheimer's Disease. 2013. Available online: https:/ / theses.cz/id/4c6vcq/ (accessed on 15 February 2019).

45. Rascati, K. Essentials of Pharmacoeconomics; Lippincott Williams \& Wilkins: Philadelphia, PA, USA, 2013.

46. Drummond, M.F.; Sculpher, M.J.; Claxton, K.; Stoddart, G.L.; Torrance, G.W. Methods for the Economic Evaluation of Health Care Programmes; Oxford University Press: Oxford, UK, 2015.

47. Travnickova, K. Economic analysis of the costs of treatment and care of patients with Alzheimer's disease. In Economics and Management in Health Care: 3rd Year: Proceedings of the Student Scientific Conference Organized by the Department of Biomedical Technology: Czech Technical University in Prague Czech Technology, CTU Publishing House: Kladno, Czech Republic, 2013; pp. 205-212.

48. Gervès, C.; Chauvin, P.; Bellanger, M.M. Evaluation of full costs of care for patients with Alzheimer's disease in France: The predominant role of informal care. Health Policy 2014, 116, 114-122. [CrossRef] [PubMed]

49. Schwarzkopf, L.; Menn, P.; Kunz, S.; Holle, R.; Lauterberg, J.; Marx, P.; Mehlig, H.; Wunder, S.; Leidl, R.; Donath, C.; et al. Costs of care for dementia patients in community setting: An analysis for mild and moderate disease stage. Value Health 2011, 14, 827-835. [CrossRef] [PubMed]

50. Drummond, M.; Sculpher, M.; Torrance, G.; O'Brien, B.; Stoddart, G. Methods for the Economic Evaluation of Health Care Programmes, 3rd ed.; Oxford University Press: New York, NY, USA, 2005.

51. Maresova, P.; Kuca, K. Missing Uniform Costs Classification for Alzheimer's Disease Treatment and Care. Curr. Alzheimer Res. 2018, 15, 1297-1303. [CrossRef]

52. bpmn.org. BPMN Specification-Business Process Model and Notation. 2016. Available online: http:/ / www.bpmn.org/ (accessed on 4 March 2019).

53. BPSim.org. 2018. Available online: http://www.bpsim.org/ (accessed on 8 March 2019).

54. Weilkiens, T.; Weiss, C.; Grass, A.R. OCEB Certification Guide: Business Process Management, Fundamental Level; Morgan Kaufmann: Burlington, MA, USA, 2011.

55. iseesystems.com. See the World Differently. 2018. Available online: http://www.iseesystems.com/ (accessed on 17 April 2019).

56. Klimova, B.; Maresova, P.; Kuca, K. Non-pharmacological approaches to the prevention and treatment of Alzheimer's disease with respect to the rising treatment costs. Curr. Alzheimer Res. 2016, 13, 1249-1258. [CrossRef]

57. Mohelska, H.; Maresova, P.; Valis, M.; Kuca, K. Alzheimer's disease and its treatment costs: Case study in the Czech Republic. Neuropsychiatr. Dis. Treat. 2015, 11, 2349. [PubMed]

58. Marešová, P.; Zahálková, V. The economic burden of the care and treatment for people with Alzheimer's disease: The outlook for the Czech Republic. Neurol. Sci. 2016, 37, 1917-1922. [CrossRef] [PubMed]

59. Zahalkova, V. Economic Aspects of Formal and Informal Care for People with Dementia. Master's Thesis, University of Hradec Kralove, Faculty of Informatics and Management, Hradec Kralove, Czech Republic, 2016.

60. mzcr. Ministry of Health of the Czech Republic. 2018. Available online: http://www.mzcr.cz/dokumenty/ 150/2017-naklady-na-vysetreni-mr-a-\%20ct_14422_1.html (accessed on 6 April 2018). 
61. Kopecky, M. Using BPMN as a Support Tool for Process Cost Management by the ABC Method. Master's Thesis, University of Hradec Kralove, Faculty of Informatics and Management, Hradec Kralove, Czech Republic, 2018.

62. Holmerová, I.; Hort, J.; Rusina, R.; Wimo, A.; Šteffl, M. Costs of dementia in the Czech Republic. Eur. J. Health Econ. 2017, 18, 979-986. [CrossRef] [PubMed]

63. Becker, J.; Janiesch, C. Restrictions in process design: A case study on workflows in healthcare. In International Conference on Business Process Management; Springer: Berlin/Heidelberg, Germany, 2007; pp. 323-334.

64. Becker, J.; Kugeler, M.; Rosemann, M. Process Management: A Guide for the Design of Business Processes; Springer Science \& Business Media: Berlin, Germany, 2013.

65. Ter Hofstede, A.H.; Weske, M. Business process management: A survey. In Proceedings of the 1st International Conference on Business Process Management, Eindhoven, The Netherlands, 26-27 June 2003; Volume 2678 of LNCS.

66. Cartelli, V.; Di Modica, G.; Manni, D.; Tomarchio, O. A Cost-Object Model for Activity Based Costing Simulation of Business Processes. In Proceedings of the 2014 European Modelling Symposium (EMS), Pisa, Italy, 21-23 October 2014; pp. 221-226.

67. Erraguntla, M.; Perakath, B.; Mayer, R.J.; deWitte, P.S. Integrating Activity Based Costing with Activity Modeling: Decision Support for Effective Cost Management; KBSI White Paper; Knowledge Based Systems, Inc.: Dayton, OH, USA, 2010; pp. 1-18.

68. Van der Aalst, W.M.; Nakatumba, J.; Rozinat, A.; Russell, N. Business Process Simulation: How to Get it Right; BPM Cent. Rep. BPM-08; BPM Center: Brisbane, Australia; Eindhoven, The Netherlands, 2008; pp. $286-291$.

69. Andreasen, S.E.; Holm, H.B.; Jørgensen, M.; Gromov, K.; Kjærsgaard-Andersen, P.; Husted, H. Time-driven activity-based cost of fast-track total hip and knee arthroplasty. J. Arthroplast. 2017, 32, 1747-1755. [CrossRef] [PubMed]

70. Keel, G.; Savage, C.; Rafiq, M.; Mazzocato, P. Time-driven activity-based costing in health care: A systematic review of the literature. Health Policy 2017, 121, 755-763. [CrossRef] [PubMed]

71. Gregório, J.; Russo, G.; Lapão, L.V. Pharmaceutical services cost analysis using time-driven activity-based costing: A contribution to improve community pharmacies' management. Res. Soc. Adm. Pharm. 2016, 12, 475-485. [CrossRef] [PubMed]

72. Rusinaite, T.; Savickas, T.; Vysockis, T.; Vasilecas, O. Selection of activities in dynamic business process simulation. Moksl. Ateitis/Sci. Lith. 2016, 8, 278-281.

73. Gawin, B.; Marcinkowski, B. How Close to Reality is the as-is Business Process Simulation Model? Organizacija 2015, 48, 155-175. [CrossRef]

74. Stankevičius, K.; Vasilecas, O. Research On Rules-Based Business Process Modelling and Simulation. Sci. Lith. Ateitis 2014, 6, 147-150.

75. Bisogno, S.; Calabrese, A.; Gastaldi, M.; Levialdi Ghiron, N. Combining modelling and simulation approaches: How to measure performance of business processes. Bus. Process Manag. J. 2016, 22, 56-74. [CrossRef]

76. Yaesoubi, R.; Cohen, T. Generalized Markov models of infectious disease spread: A novel framework for developing dynamic health policies. Eur. J. Oper. Res. 2011, 215, 679-687. [CrossRef] [PubMed]

77. Sköldunger, A.; Fastbom, J.; Wimo, A.; Fratiglioni, L.; Johnell, K. Impact of inappropriate drug use on hospitalizations, mortality, and costs in older persons and persons with dementia: Findings from the SNAC study. Drugs Aging 2015, 32, 671-678. [CrossRef] [PubMed]

78. Gustavsson, A.; Green, C.; Jones, R.W.; Förstl, H.; Simsek, D.; de Vulpillieres, F.d.R.; Luthman, S.; Adlard, N.; Bhattacharyya, S.; Wimo, A. Current issues and future research priorities for health economic modelling across the full continuum of Alzheimer's disease. Alzheimer's Dement. 2017, 13, 312-321. [CrossRef] [PubMed]

(C) 2019 by the authors. Licensee MDPI, Basel, Switzerland. This article is an open access article distributed under the terms and conditions of the Creative Commons Attribution (CC BY) license (http:/ / creativecommons.org/licenses/by/4.0/). 